\title{
A tecnociência pós-moderna e o trabalho de cuidado
}

\begin{abstract}
Ariel Salleh ${ }^{1}$
Resumo: este artigo trata de um debate atual da teoria feminista socialista a partir dos posicionamentos sobre "mulher", "trabalho" e "natureza" no trabalho da teórica estadunidense Donna Haraway e de suas seguidoras europeias. Uma leitura crítica mostra suas análises pós-moderna inúteis à ação política. O trabalho de cuidado tradicionalmenteimputadoàs mulhereséuma mediação com a natureza por meio do trabalho doméstico no Norte econômico e da agricultura de subsistência no Sul econômico. Enquanto tal, suas qualificações e valores constituem uma ciência vernacular tácita indispensável às lutas políticas por justiça e sustentabilidade. Contra isso: a lúdica celebração pós-moderna de Haraway da tecnociência patriarcal é involuntariamente neocolonial. Ademais, a preocupação idealista com o discurso pode erodir a confiança das mulheres que resistem nos movimentos de base, assim como a globalização neoliberal consome e degrada a terra. $\mathrm{O}$ artigo argumenta a favor de um ecofeminismo materialista e de formas de conhecimento enraizadas na reprodução cotidiana da vida em comum.
\end{abstract}

Palavras-chave: Pós-Modernismo; Tecnociência; Ecofeminismo Materialista.

Abstract: the article visits an ongoing debate in socialist feminist theory. It concerns attitudes to 'women', labour', and 'nature' in the work of US theorist Donna Haraway and her European followers. A critical reading shows their postmodern analysis unhelpful to political action. Women's traditionally ascribed care labours mediate nature

\footnotetext{
${ }^{1}$ Professora associada do Departamento de Economia Política da Universidade de Sydney. E-mail: ariel.salleh@sydney.edu.au. Tradução: Murillo van der Laan. Revisão: Mariana Shinohara Roncato, Rafael Toitio e Felipe Milanez.
} 
by domestic work in the economic North and subsistence farming in the economic South. As such, their skills and values constitute a tacit vernacular science indispensable to political struggles for justice and sustainability. Against this: Haraway's playful postmodern celebration of capitalist patriarchal technoscience is unwittingly neocolonial. Further, the idealist preoccupation with discourse can undercut women's confidence as grassroots resisters, just as neoliberal globalisation consumes and degrades the earth. The article argues for a materialist ecofeminism and ways of knowing that are grounded in the everyday reproduction of common life.

Keywords: Postmodernism; Technoscience; Materialist Ecofeminism.

A história do feminismo é marcada por diversos paradigmas com diferentes fundamentos epistemológicos e implicações políticas. Entre esses, o ecofeminismo materialista combina o pensamento socialista, os conhecimentos de gênero e a consciência ecológica (SALLEH, 2017). Em contraste, o paradigma feminista pós-moderno prioriza a linguagem na construção social da vida cotidiana. Isso, e um foco nas "especificidades", seguindo Foucault, significa um afastamento de grandes narrativas, como o marxismo, e também de conceitos universalizantes como mulher, trabalho ou natureza. Dessa forma, a "virada linguística" enfraquece potencialmente as lutas por justiça e por meios de subsistência sustentáveis. Issoé perceptívelem antologias norte-americanas clássicas como Feminism/Postmodernism de Linda Nicholson, onde há poucas indicações do colapso dos sistemas de apoio à vida global provocado pelo militarismo, o desenvolvimento industrial e pelo livre comércio (NICHOLSON, 1990). O ecofeminismo é uma resposta direta aos danos colaterais da modernização ocidental - aquecimento global, rios poluídos, perda de biodiversidade, alergias infantis. Enquanto rejeição existencial à mega-máquina do patriarcado capitalista, o ecofeminismo é parte da aliança mundial dos movimentos por mudança, exaltando a diversidade cultural e a ética bio-regional ${ }^{2}$.

${ }^{2}$ Por exemplo: Isla, 2005; Mallory, 2006; World Rainforest Movement, 2017.

176 A tecnociência pós-moderna e o trabalho... 
O livro Simians, Cyborgs, and Women mostra a teórica americana Donna Haraway em seu ápice criativo, enquanto pensadora pósmoderna. Ela reivindica um alinhamento com o socialismo e com o ecofeminismo, mas considera, por outro lado, uma epistemologia apreendida a partir da experiência da exploração como um "empirismo naïve" (HARAWAY, 1991; 1997). Isso, por sua vez, colide com sua defesa de fronteiras discursivas "permeáveis" entre os materialismos da "biota", das "tecnologias" e dos "textos"; e, ainda, com "a necessidade de manter alguma fundamentação não-discursiva de 'sexo' e 'natureza'", como defende o feminismo radical de Evelyn Fox Keller (HARAWAY, 1991, p. 250; KELLER, 1987). Trata-se de uma concessão da parte de Haraway de que algumas coisas poderiam ser imediatamente conhecidas pelos sentidos? O discurso não seria tão total como os construcionistas sociais sugerem?

Haraway (1991, p. 178) ecoa a conhecida "hierarquia das ciências" positivista quando argumenta que: "não há nenhuma separação fundamental, ontológica, em nosso conhecimento formal entre máquina e organismo, técnico e orgânico". Mas por essa lógica, se as máquinas são simplesmente extensões do "corpo do homem", próteses inocentes, então uma instalação nuclear é tão benigna quanto um formigueiro? De modo semelhante, em Primate Visions, assim ela descreve a emergência da dominação eurocêntrica:

no começo, havia a diferença, e então começou a luta de algumas mentes para obter vantagens sobre outras. Esse é um fragmento de narrativas estratégicas, narrativas edípicas e narrativas tecnológicas modernas, onde está em jogo a sobrevivência - os futuros possíveis -, em um mundo tecno-fetal de "quase-mentes" [...] Crianças, programas de computadores com inteligência artificial e primatas não-humanos [...] (HARAWAY, 1989, p. 376). 
O tom distanciado aqui transmite tanto um relato sem julgamentos quanto uma ironia feminista. A despeito de Haraway ter reservas com as epistemologias standpoint do feminismo socialista, ela toma emprestado sua premissa de que o conhecimento deve ser socialmente "situado". Sua própria "localização histórica" é designada como "branca, qualificada profissionalmente, classe média, feminina, radical, norte-americana, de meia idade" (HARAWAY, 1991, p. 155). Mas, ao mesmo tempo, ela reclama do valor que as feministas dão ao aprendizado pela experiência de vida. Então a questão da "responsabilidade" situada nunca é realmente resolvida em seus escritos. Se as questões cruciais são: "por que uma teoria particular é construída? Para quem? E como?", Haraway não as responde diretamente.

As teóricas dos sistemas não se sentem confortáveis com noções "humanistas" como subjetividade e integridade, mas o texto "sem autor" de Haraway é traído por um contra-discurso em suas notas de rodapé. Claramente um sujeito está vivo e bem, com financiamento de diversas fundações, círculos de leitura e amizades acadêmicas em Santa Cruz, EUA. As notas de rodapé falam de uma infraestrutura materialmente corporificada cuidando da aparente autonomia do "texto", e essa dissociação psicológica entre o autor e a palavra escrita resulta em uma metodologia um tanto esquizoide.

"nosso" problema é como ter simultaneamente uma perspectiva de uma contingência histórica radical para todas as reivindicações de conhecimento e sujeitos cognoscentes, uma prática crítica para reconhecer nossas próprias "tecnologias semióticas" para a formação de significados, e um compromisso com o não-absurdo [no-nonsense] para reflexões fidedignas do mundo "real", uma perspectiva que pode ser parcialmente compartilhada e amistosa com projetos, em todo o mundo, de liberdade finita, abundância material, significado modesto no sofrimento e felicidade limitada (HARAWAY, 1991, p. 155).

178 A tecnociência pós-moderna e o trabalho... 
Há um vácuo quando se trata de combinar uma política textual com preocupações materiais como a perda de acesso à água potável comunal ou o estupro na guerra ${ }^{3}$.

Não obstante, algumas feministas transeuropeias adotaram essa abordagem em Women, enviroment and sustainable development. Aqui, Rosi Braidotti, Ewa Charkiewicz, Sabine Hausler e Saskia Wieringa, buscaram uma análise pós-moderna dos resultados da Rio92. A avaliação delas das relações entre mulheres e desenvolvimento, patrocinada pelas Nações Unidas, acata a reivindicação de Haraway por uma "comunidade anti-relativista, específica, de sujeitos semiótico-materiais historicamente localizados", buscando conexões e articulações de maneira não-etno/gênero-centrada" (BRAIDOTTI et al, 1994, p. 55). Com sugestões indiretas da "ruptura epistemológica" althusseriana, Braidotti et al insistem que o discurso feminista abandonou o objetivo humanista da "emancipação". Todavia, elas também falam sobre "empoderar o ser/tornar-se [be-coming] sujeito das mulheres" (BRAIDOTTI et al, 1994, p. 48). Como feministas pósmodernas, elas estão preocupadas em "como identificar pontos de saída do universalismo implícito no sistema patriarcal ou 'falogocêntrico' e das maneiras dualistas ou binárias de pensar que o caracterizam" (BRAIDOTTI et al, 1994, p. 41). Para parafrasear o dilema: se o discurso é um círculo cognitivo totalizante fechado, como poderemos reordenar "o código" e deixar para trás a dominação? A isso uma ecofeminista materialista responderia que se não há saída a partir da "palavra falada", talvez os duplos vínculos dessa lógica podem ser dissolvidos através de modalidades mais profundas de sentimentos (SALLEH, 1982)?

Uma aplicação escandinava de Haraway é o estudo de Mette Bryld e Nina Lykke (2000) Cosmodolphins: feminist cultural studies of technology, animals and the sacred. Tal estudo também é concebido

\footnotetext{
${ }^{3}$ Noel Sturgeon (1997), uma das alunas de Haraway, procura suprimir essa lacuna em sua tese Ecofeminist Nature, publicada pela editora Routledge.
} 
para desconstruir a narrativa do patriarcado capitalista e seus efeitos cotidianos. Em consonância com a maioria das ecofeministas, essas autoras indicam que o condicionamento psicológico masculino está fortemente implicado na crise ecológica global, assim como informa o machismo, o classismo, o racismo e a discriminação por idade. Portanto, no século XXI, um dilema comum colocado aos homens brancos de classe média reflexivos é: como podem aqueles que são diferentes de nós - como trabalhadores, mulheres, indígenas, crianças, animais, pedras -, serem também semelhantes a nós? Há alguma maneira da subjetividade masculina se relacionar com esses "outros" para além daquela voltada a controlar suas "naturezas selvagens"? Bryld e Lykke reconhecem como suas antecedentes as ecofeministas estadunidenses Carolyn Merchant (1980), Carol Adams (1990), e Karen Warren (1990). E a crítica delas da tecnociência tem muito em comum com o posicionamento em Woman and Nature, de Susan Griffin (1987), um estudo sobre como as mulheres são oprimidas por serem "naturalizadas". Mas as autoras de Cosmodolphins parecem não conhecer escritos ecofeministas anteriores que, como o delas próprio, usa radicalmente a écriture féminine desconstrutiva (MARX e COURTIVRON, 1981).

Uma sociedade patriarcal somente pode sobreviver controlando a fertilidade das mulheres. Desse modo, a religião judaico-cristã designou homens como administradores da natureza e as mulheres como seus bens (GRAY, 1979). Uma imagem de uma Mãe Natureza indisciplinada que precisa ser dominada intensifica-se com a ascensão da ciência iluminista. Bryld e Lykke (2000, p. 198) observam que as práticas de comando e controle industriais levam adiante essa dinâmica libidinal como uma substituição metonímica nos discursos das ciências aeroespaciais, nos estudos sobre golfinhos e na astrologia. Elas avaliam esse deslocamento linguístico como uma reação subconsciente à posição central das mulheres na reprodução da espécie. A Tecnologia-ciência modernidade-branquitudemasculinidade fornecem "estórias originárias descorporificadas

$\overline{180}$ A tecnociência pós-moderna e o trabalho... 
que ocultam, falsificam e mentem sobre o papel ativo da matéria e dos corpos (femininos)" (BRYLD e LYKKE, 2000, p. 219). Assim, uma histeria reprimida, profundamente presente no interior da masculinidade eurocêntrica, é sublimada pela dominação dos poderes do 'outro/mãe' [m/other] originário.

Bryld e Lykke percorrem um espaço entre a análise pósmoderna do discurso e o ecofeminismo materialista de maneira mais confortável do que Braidotti et al. Para as últimas a ênfase em "variáveis reguladoras" como gênero, classe e raça tem um foco antropocêntrico. As ecofeministas dão preferência a uma política holística que inclua outras espécies e a "natureza" em geral. Essa ruptura ecocêntrica com a dominação ocidental distingue o ecofeminismo de outros paradigmas feministas. Como Ynestra King (1989) aponta, mesmo as teorias multifatoriais do feminismo socialista standpoint de Alison Jaggar e Nancy Hartsock "não tratam a dominação da natureza como uma categoria significante". Dito isso, as últimas ao menos sintetizam uma posição a partir da qual mulheres vivas, reais, podem realizar reivindicações políticas, e elas o fazem de maneira que é histórica e materialista e não biologicamente determinista ou essencialista.

Paralelamente à rejeição do conceito de "mulher", muitas feministas pós-modernas também menosprezam o conceito de "natureza". Contra um tratamento literal, quase positivista, dos "universais", as pós-modernas celebram a multiplicidade das diferenças, se "regozijam na confusão das fronteiras e da responsabilidade em construí-las" (HARAWAY, 1991, p. 150). Ainda assim, durante esse processo de recontextualizar os "universais", as ativistas ainda precisam ser capazes de "falar" - mesmo enquanto usam palavras que estão em processo de contestação e re-definição. A despeito de sua sofisticação linguística, as pós-modernas frequentemente discutem universais capitalistas patriarcais como "mulher" e "natureza" de maneira não dialética, como se elas fossem "fatos sociais" durkheimianos.

Esse hábito decorre dos mesmos binarismos hegemônicos que deformam a razão masculinista. Bem entendido: velhos dualismos 
como sexo/gênero, natureza/cultura, produção/reprodução, eu/ outro, desenvolvido/subdesenvolvido, são impostos às sociedades contemporâneas através dos discursos patriarcais do capitalismo, do liberalismo e da ciência. Para evitar qualquer "essencialismo", a dualidade artificial do "sexo versus gênero" recebe muita atenção das feministas pós-modernas, mas elas deixam o potencial radical ecológico do binário "humanidade versus natureza" para que as ecofeministas lidem com ele. Nesse trabalho, as ecofeministas de fato "abrem as fronteiras" e as restrições sobre as identidades das mulheres, homens e outros. Mas as ecofeministas não "des-naturam" necessariamente o corpo sexuado hibridizando-o, como muitos profissionais liberais urbanos privilegiados o fazem em sociedades de alta tecnologia. O corpo fértil não está tão prontamente neutralizado no Sul global, onde o sexo biológico é um professor que deixa a maioria das mulheres à mercê das forças culturais, sócio-econômicas e ecológicas.

A incapacidade de muitas feministas pós-modernas em realizar um duplo movimento reflexivo no pensamento é abordada por Diana Fuss (1989, p. 118), em Essentially Speaking:

[...] precisamos simultaneamente teorizar os lugares essencialistas a partir dos quais falamos e desconstruir esses espaços para evitar que eles se solidifiquem. Tais movimentos duplos envolvem, mais uma vez, a responsabilidade de historicizar, de examinar cada desdobramento da essência, cada apelo à experiência, cada apelo à identidade dentro do complicado quadro contextual em que é feito.

Em contraste, a estratégia de Haraway tem sido ejetar palavras problemáticas e criar outras novas, daí "o ciborgue": o nome usado por ela para nossa condição pós-moderna como híbridos humanomáquinas tecnocientíficos. Esse distanciamento da teoria feminista dos libidinalmente "carregados status simbólico e social das mães" pode conquistar alguns estudantes rebeldes, mas seu efeito político é empurrar para o subterrâneo as "mulheres que falam" e suas

182 A tecnociência pós-moderna e o trabalho... 
materialidades corporificadas. A discussão de Braidotti et al. (1994) sobre a "intersecção entre o natural e o cultural" permanece do mesmo modo abstrata e desconectada do cotidiano. Contra a análise estática, sincrônica, e linguística dos textos - de fato, contra a própria vida como um "texto" - um ponto de vista político ecofeminista é processual, expressando historicamente as energias vividas.

Uma recente contribuição feminista francesa, de Émilie Hache, busca restaurar essa abordagem ao fazer político neste momento do patriarcado capitalista (HACHE, 2017). O estudo clássico de Sandra Harding Whose science? Whose knowledge? fornece argumentos impressionantes para a epistemologia feminista standpoint (HARDING, 1991). Ela insiste que a localização dolorosamente contraditória das mulheres tanto dentro como fora da esfera pública aguça sua percepção radical. As atividades específicas de gênero das mulheres moldam o seu pensamento como uma nova voz política. Como virtualmente estranhas, marginais à economia patriarcal capitalista global, como trabalhadoras de cuidado não remuneradas, as mulheres têm maiores probabilidades de serem observadoras altamente objetivas deste sistema. Como um grupo oprimido, elas não possuem nenhum interesse manifesto em mascarar essas estruturas sociais corruptas (ODIH, 2016). Enquanto aquelas que desempenham funções de trabalho que "medeiam a natureza" - seja através de trabalho doméstico no Norte econômico ou de agricultura de subsistência no Sul econômico, as qualificações, conhecimentos e valores das mulheres são indispensáveis para debates cidadãos sobre sustentabilidade e justiça.

$\mathrm{O}$ que poderia contentar mais os defensores da narrativa do patriarcado capitalista do que a anulação da "mulher" e sua substituição pelo ciborgue? Em certo sentido, esse movimento já está em andamento através das pesquisas das grandes corporações sobre tecnologias reprodutivas. Essa utopia desgenerificada é precisamente aquilo que Haraway busca. De maneira semelhante, Judith Butler (1990) escreve que nós mal sabemos o que queremos dizer quando 
usamos a categoria "mulher". Esse raciocínio acadêmico descontextualizado tem agora intimidado uma geração de pesquisadoras, muitas retirando completamente a palavra "mulher" do léxico feminista. Gayatri Spivak (1987; FUSS, 1989) socorreu prováveis ativistas propondo que elas usem um "essencialismo operacional" para fins práticos, mas, novamente, essa é uma solução pósmoderna muito desconectada. É preocupante também que muitas feministas não conseguem discernir quando palavras como "mulher" ou "natureza" estão sendo usadas estrategicamente, ironicamente ou literalmente. E muitas ainda tentam usar a palavra "essencialismo" sem compreender realmente o que ela significa ${ }^{4}$. O raciocínio dualista "ou/ou" nos quais os pós-modernos se apoiam para criticarem o ecofeminismo pode ele mesmo ser caracterizado como um "essencialismo ideológico" (SALLEH, 1984; 1991).

Quando ecofeministas interrogam construtos como "mulher" ou "homem" é para "ressituá-los" em uma perspectiva ecológica. O termo ecofeminismo implica tanto uma ecologia como um feminismo - uma identidade política com fronteiras abertas. Por outro lado, Butler, convergindo com a filosofia ciborgue de Haraway, apresenta a noção de "mulher" como regressiva, denotando um despejo prematuro de possibilidades futuras. Ela escreve que no patriarcado capitalista ocidental, a condição de sujeito não é uma opção para um corpo que é sexuado como "mulher". Isso porque essa condição "já é sempre sexuada como masculina", o que demanda uma hierarquia de sustentáculos. Não é essa uma forma derrotista de "política identitária"? Butler identifica sua genealogia na psicanálise pós-estruturalista lacaniana, apesar de, ao descrever o gênero como um mero "efeito de verdade" do discurso, uma "performance", seu modelo torna-se tão estático e total quanto o funcionalismo da teoria dos papéis sociais norte-americana dos anos 1950.

\footnotetext{
${ }^{4}$ Para uma forte refutação, ver Godfrey, 2005.
}

184 A tecnociência pós-moderna e o trabalho... 
Para a maioria das mulheres que não habitam o espaço ciborgue dos corpos tecnologicamente controlados, esses questionamentos textuais são um tanto cruéis. Haraway (1991, p. 138) está certa quando escreve que "o que faz uma mulher é a relação específica de apropriação por um homem". Mas ela, então, acrescenta: "a insistência na vitimização como o único terreno para insights, já provocou prejuízos suficientes" (1991, p. 157). Talvez, ao voltar-se contra a vitimização, ela esteja na verdade protestando contra seu próprio aprisionamento intelectual em uma concepção "demasiadamente socializada" do que uma mulher é? As ecofeministas materialistas, ao contrário, consideram a violência sexual e a exploração econômica sobre as mulheres como catalisadoras da formação deum sujeito político psicologicamente resistente (SALLEH, 1982). Ao mesmo tempo, este sujeito, que faz a si mesmo, carrega habilidades que são inestimáveis para a gestão das relações vivas entre humanos e natureza. Se as estatísticas internacionais do trabalho estiverem corretas, as mulheres, de fato, seguram mais da metade do céu. Longe de uma vitimização, as ecofeministas reconhecem a agência política das mulheres como uma força crítica nos movimentos por uma globalização alternativa, com muitas assumindo a liderança na Rio+20, no Fórum Social Mundial ou nas reuniões da Conferência das Partes (COP) (SALLEH, 2004).

A luta dos homens do patriarcado capitalista para limitar seus "outros naturalizados" - mulheres, indígenas, a terra - coloca o neocolonialismo frente à frente com a biotecnologia. Bryld e Lykke observam que, seguindo a definição da Bruntland Commission de espaço e oceanos como commons globais, as Nações Unidas, como um "panóptico", começaram a monitorar autoritariamente a nova ordem "biopolítica" desde o espaço. Simultaneamente, as agências da ONU, guiadas pela familiar "mão invisível", voltaram sua atenção ao cerne da seleção da vida - o controle de populações e o desmatamento. Assumiu-se até mesmo que, para manter a "defesa militarizada" da masculinidade ocidental, o recurso às jazidas minerais extraterrestres seria necessário. A terraformação [terraforming] ou a "domesticação" 
de outros planetas ajudaria a proteger a Terra. A fascinação de Haraway com a tecnociência está tacitamente casada com este modelo de alto crescimento e ela não parece ter autoconsciência de sua própria "localização" na terra do liberalismo do silício.

Nenhuma voz do Sul econômico tem sido tão eloquente sobre a tecnociência ocidental quanto a ecofeminista indiana Vandana Shiva. Em relação à destruição ambiental, Haraway invoca a fantasia científica de uma Gaia que se auto-resgata; mas de acordo com a crítica de Shiva ao "maldesenvolvimento", o mundo não apenas "resiste" à redução (SHIVA, 1989). Isso é perceptível na dizimação da agricultura indiana pelas transferências tecnológicas da Revolução Verde, a partir do Norte global. Mas a "consciência feliz" do deslocamento high tech de Haraway da "reprodução" para a "replicação genética" ignora os fundamentos misóginos profundamente falhos da ciência ocidental em sua fase das grandes corporações 5 . Haraway deixa de lado a pesquisa ecofeminista de Merchant sobre a inquisição, a caça às bruxas sistemática que perseguiu as mulheres conhecedoras, e o expurgo que tornou possível a "revolução" da ciência mecanicista do patriarcado capitalista. Como se continuando essa tradição, a tecnociência de Haraway também rompe com o organicismo (HARAWAY, 1997, p. 257). Isso tem o efeito de marginalizar "outras" formas de conhecer como o buen vivir ou o ubuntu (SOLON, 2017).

Retornando ao que as socialistas chamam de "a questão da mulher", por que as pós-modernas insistem que as atividades políticas das mulheres sejam de-codificadas e des-naturalizadas? Qual o tipo de auto-aversão que perpetua a hierarquia de valores masculinista do mental e do manual, do discurso sobre a matéria, da cultura sobre a natureza? Por que deveria ser degradante dizer que as mulheres lutam por paz como "mães", enquanto não é degradante dizer que elas lutam pelo meio ambiente enquanto "agricultoras"

\footnotetext{
${ }^{5}$ Dito isso, uma de suas doutorandas afirma que a "mobilização dos recursos" capitalista patriarcal é "um segundo nascimento do Homem através da homogeneização de todo o corpo do mundo" (SOFOULIS, 1988).
}

\begin{tabular}{l|l}
\hline 186 & A tecnociência pós-moderna e o trabalho...
\end{tabular} 
ou "cidadãs"? A acusação pós-moderna de "maternalismo" é abusiva à grande maioria das mulheres em todo mundo, cujos trabalhos são sobrecarregados por dependentes carentes. As ecofeministas podem concordar com o programa feminista pós-moderno de reivindicar "identidades desprezadas". Mas a identidade da mãe teria de ser, entre todas, a categoria política mais universalmente caluniada - e muita da literatura feminista é cúmplice disso ${ }^{6}$. Ela cria detritos emocionais a serem absorvidos pela teoria feminista.

Adrienne Rich nos diz em Of woman born: "o corpo foi tornado tão problemático para as mulheres que frequentemente tem parecido mais fácil dar de ombros e seguir como um espírito descorporificado" (RICH, 1977). Isso explica o refúgio de Haraway na utopia dos ciborgues, pós-gênero, meio-humano-meio-máquina? Qual sentido prático tem o ícone do ciborgue para as mulheres cujas terras foram cercadas pelo agronegócio? Qual o uso do ciborgue para as mulheres cujas vizinhanças são terrenos baldios industriais tóxicos? Haraway afirma que é irresponsável nas atuais condições históricas "perseguir estórias anti-científicas sobre a natureza que idealizam a mulher" (HARAWAY, 1991, p. 107). Mas sob condições de subsunção do patriarcado capitalista, a quais interesses servem tal avaliação? Não é "irresponsável" desacreditar a política espontânea através da qual as mulheres em todo mundo estão assumindo a liderança pela vida na terra? Uma transvaloração historicamente enraizada das competências laborais materialmente corporificadas das mulheres não deve ser confundida com idealização.

A moda da desconstrução linguística silencia "mulheres" como nada mais que corpos discursivamente fabricados - e o seu materialismo é a materialidade do "texto". É encorajador, ao menos, encontrar construcionistas sociais como Braidotti et al. (1994) revisando atitudes negativas relacionadas a expressão "mulheres do terceiro mundo". Elas reconhecem que as mulheres do Sul global não

\footnotetext{
${ }^{6}$ Ver, por exemplo, CUOMO, 2001; MCGREGOR, 2004.
} 
mais são as vítimas arquetípicas "na base de uma cascata de identidades negativas". De fato, tais mulheres são altamente experientes em uma ciência vernacular de gestão ambiental. O ecofeminismo materialista de Veronika Bennholdt-Thomsen em There is an alternative destaca o compromisso político de tais mulheres com a proteção da biodiversidade, enquanto guiam suas irmãs dos países industrializados em direção a uma ecopolítica mais inclusiva (BENNHOLDTTHOMSEN et al, 2001). Considerada a atual colaboração Norte/Sul entre as ecofeministas, nada tem sido tão fútil como o debate pósmoderno sob as "Mulheres do terceiro mundo" e o "olhar" feminista. O Norte opulento revela sua amarra idealista e de classe média quando seus acadêmicos argumentam que não existe algo como a mulher do Terceiro Mundo (SALLEH, 1990). Essas mesmas feministas argumentariam que não há algo como o imperialismo neoliberal?

Rejeitar o ponto de vista experiencial das mulheres trabalhadoras do Sul econômico, com base na consideração de que ao aceitá-lo endossa-se sua "alteridade" patriarcalmente atribuída, é simplesmente uma aceitação não crítica da lógica dominante ${ }^{7}$. Essa inibição pósmoderna - mesmo a famosa questão de Spivak: como pode o subalterno falar? - expressa um certo tipo de culpa intelectual sobre mulheres reconhecidas apenas como "informantes" ou como exemplares de uma "voz". Quando europeias, como Braidotti, insistem no "posicionamento múltiplo" do cognoscente para serem sensíveis às diferenças de poder, elas ainda veem as "outras mulheres" como objetos de pesquisa de "agências internacionais"? Tais pesquisas são realmente necessárias ou é hora de aprender com essas irmãs no Sul global?

Algumas ecofeministas materialistas encontram um terreno comum nos trabalhos regenerativos das mulheres subalternas e no trabalho das mães e cuidadoras não remuneradas no Norte.

\footnotetext{
${ }^{7} \mathrm{Não}$ apenas as pós-modernas, mas também as feministas desenvolvimentistas podem ceder a tal tendência. Ver SALLEH, 1996.
}

188 A tecnociência pós-moderna e o trabalho... 
Em Women: the last colony, Maria Mies, Veronika Bennholdt-Thomsen e Claudia von Werlhof fazem uma análise neomarxista ímpar desse terreno político e sua relação de suporte do sistema econômico do patriarcado capitalista (MIES et al, 1988). Como Mariarosa Dalla Costa e outras demonstraram, os serviços domésticos gratuitos que reproduzem diariamente "o trabalhador" são apropriados e fluem diretamente para a geração de mais-valia (DALLA COSTA, 1972). Em áreas não-industriais do Sul global, o provisionamento doméstico rural pode ser mais autônomo que o das donas de casa no Norte global.

Haraway não gosta do "privilégio dado ao trabalho", particularmente em perspectivas feministas de como se chega ao conhecimento (HARAWAY, 1991, p. 158). Para ela, o trabalho é um "momento ontológico" e, assim, qualquer discussão sobre ele será "essencialista". Essa desconexão do substrato material que sustenta a sociedade como um todo, sem mencionar a vida intelectual mesma, é de fato problemática. Ela compromete a própria inclinação de Haraway ao socialismo e a distancia dos trabalhadores e mães em aliança para a mudança social. Se Haraway opõe-se à priorização do "trabalho", as ecofeministas materialistas mudam o centro da análise da produção para o "trabalho reprodutivo". Haraway observa que a reprodução tornou-se o local privilegiado para a contestação política pós-moderna. No entanto, a despeito de reconhecer o cerne "biocultural" da divisão generificada do trabalho sob a globalização, ela resiste à caixa de Pandora da "política reprodutiva".

Nesse momento, os leitores podem ficar intrigados ao encontrar Haraway endossando uma teórica do standpoint: "não deveria levar décadas à teoria feminista para perceber o inimigo aqui. Nancy Hartsock deixou isso cristalino em seu conceito de masculinidade abstrata" (HARAWAY, 1991, p. 186; HARTSOCK, 1983). Por que uma construcionista social se curvaria a um construto essencializante como "masculinidade abstrata" e recusaria, então, à "mulher" universal um lugar no texto? De maneira similar, ela rejeita a campanha de salários para o trabalho doméstico como uma anterior "política feminista 
[que] reivindicou a inclusão total das mulheres na política do corpo, a partir das funções maternais na economia doméstica estendidas ao mundo público" (HARAWAY, 1991, p. 210). Desde o princípio, a finlandesa Hilkka Pietila (PIETILA, 1985) ou a neozelandesa Marilyn Waring (1988) em Counting for nothing documentaram como o modo de produção do patriarcado capitalista e sua "informática da dominação" é completamente dependente do trabalho relacional das mulheres. Essas intervenções pioneiras foram fundamentais para a recente "virada ao cuidado".

Abordando o neoliberalismo global, Bryld e Lykke (2000, p. 27) descreveram a si mesmas como "cidadãs de uma pequena e pouco heroica nação [...] olhando a partir das margens" da "fronteira" do complexo pós-industrial. Do modo como elas veem:

[...] as finadas utopias da modernidade europeia e americana, e a definhante crença em sua missão mundial tecno-política "civilizatória" persiste, por assim dizer, postumamente, dando legitimidade aos atos canibais e às novas buscas por territórios selvagens abundantes em recursos (BRYLD e LYKKE, 2000, p. 22).

As autoras são muito bem sucedidas em demonstrar o "truque divino" da tecnociência da Nasa ao observar o planeta azul lá embaixo. Mas, como sua mentora Haraway, elas perpetuam a "perspectiva de lugar nenhum", com sua rejeição pós-estruturalista da epistemologia standpoint (BRYLD e LYKKE, 2000, p. 30). Talvez o problema decorra do fato de que sua disciplina de estudos culturais seja concebida para desestabilizar o mundo das ideias, e não para libertar das estruturas sociais opressivas o longo sofrimento dos corpos materiais. Bryld e Lykke não oferecem nenhuma base existencial para a práxis. Haraway fala de formas utópicas de subjetividade política resistindo ao "fechamento metafísico". Mas a "morte do sujeito" pós-estruturalista é precisamente um fechamento - o corpo um mero "agrupamento estratégico" degenes.A filosofia ciborgueevita qualquer re-identificação

\begin{tabular}{l|l}
\hline 190 & A tecnociência pós-moderna e o trabalho...
\end{tabular} 
ecofeminista com a natureza, preferindo uma "re-invenção" da natureza fundida com máquinas feitas pelo homem. Haraway escreve: "talvez, ironicamente, nós possamos aprender com nossas fusões com animais e máquinas como não ser Homem" (HARAWAY, 1991, p. 173). Para as ecofeministas, essa concessão à tecnociência é uma contradição em termos. Uma vez que os homens ocidentais definiram a si mesmos precisamente pelo projeto tecnológico de remodelarem a natureza, por que deveriam as mulheres aceitarem esse caminho arrogante à emancipação?

Enquanto o século XX arma o alcance colonizador da globalização, os leitores podem se perguntar sobre a sofisticação complacente de complexos "campos abertos", "jogos" cruzados, "verdades parciais" e dispersões foucaultinas de poder... A incursão na tecnociência como uma "semiose materializada" quase reduz a análise sociológica a uma "coleção heterogênea de adesivos para carros" (JAMIESON, 1991, p. 583). O que significa dizer que "o surrealismo ciborgue - é o espaço excessivo da tecnociência - um mundo em cuja gramática podemos estar inseridos, mas onde nos é permitido, e de fato temos a capacidade, tanto de incorporar quanto exceder suas representações e detonar sua sintaxe" (HARAWAY, 2000, p. 122)? Quem é "nós"? Certamente esse mantra mistifica e legitima o status quo. $\mathrm{O}$ gigante high tech incontrolável de Haraway, faminto por carbono, colide com os esforços populares para a construção de futuros alternativos. A satisfação com a replicação aleatória e o hibridismo planejado pode apenas estilhaçar a teia da vida sobre a terra. 


\section{Referências bibliográficas}

ADAMS, C. The Sexual Politics of Meat. Nova York: Continuum, 1990.

BENNHOLDT-THOMSEN, V. et al (org.). There Is An Alternative. Londres: Zed Books, 2001.

BRAIDOTTI, R. et al. Women, the Environment and Sustainable Development. Londres: Zed Books, 1994.

BRYLD, M. e LYKKE, N. Cosmodolphins: Feminist Cultural Studies of Technology, Animals and the Sacred. Londres: Zed Books, 2000.

BUTLER, J. Gender Trouble, Feminist Theory, and Psychoanalytic Discourse. In: NICHOLSON, Linda (org.). Feminism/ Postmodernism. Nova York: Routledge, 1990.

CUOMO, C. Still Messing with Mother Nature, Hypatia, vol. 16, n. 3, p. 149-56, 2001.

DALLA COSTA, M. Women and the Subversion of the Community. In: . e JAMES, S. The Power of Women and the Subversion of the Community. Bristol: Falling Wall Press, 1972.

FUSS, D. Essentially Speaking. New York: Routledge, 1989.

GODFREY, P. Diane Wilson v Union Carbide: Ecofeminism and the Elitist Charge of Ecofeminism. Capitalism Nature Socialism, vol. 16, n. 4, p. 37-54, 2005.

GRAY, E. D. Green Paradise Lost. Wellesley: Roundtable Press, 1979.

$\overline{192} \quad$ A tecnociência pós-moderna e o trabalho... 
GRIFFIN, S. Woman and Nature: The Roaring Inside Her. Nova York: Harper, 1987.

HACHE, E. (org.). Reclaim. Paris: Cambourakis, 2017.

HARAWAY, D. How Like a Leaf. Nova York: Routledge, 2000.

Modest_Witness at Second_Millenium. FemaleMan_Meets_ OncoMouse. Nova York: Routledge, 1997.

Primate Visions. Nova York: Routledge, 1989.

Simians, Cyborgs, and Women. Nova York: Routledge, 1991.

HARDING, S. Whose Science? Whose Knowledge?. Milton Keynes: Open University Press, 1991.

HARTSOCK, N. Money, Sex and Power. Boston: North Eastern University Press, 1983.

ISLA, A. Conservation as Enclosure: An Ecofeminist Perspective on Sustainable Development and Biopiracy in Costa Rica. Capitalism Nature Socialism, 2005, vol. 16, n. 3, 2005, p. 49-61.

JAMIESON, D. The Poverty of Postmodernist Theory. University of Colorado Law Review, vol. 62, n. 3, 1991, p. 577-95.

KING, Y. Healing the Wounds: Feminism, Ecology, and Nature/Culture Dualism. In: JAGGAR, Alison e BORDO, S. (org.). Gender/Body/ Knowledge: Feminist Reconstructions of Being and Knowing. New Brunswick: Rutgers University Press, 1989. 
MALLORY, C. Ecofeminism and Forest Defense in Cascadia. Capitalism Nature Socialism, vol. 17, n. 2, 2006, p. 32-49.

MARX, E. e COURTIVRON, I. (org.). New French Feminisms. Brighton: Harvester, 1981.

MCGREGOR, S. From Care to Citizenship: Calling Ecofeminism Back to Politics. Ethics and the Environment, v. 9, 2004.

MERCHANT, C. The Death of Nature: Women and the Scientific Revolution. São Francisco: Harper, 1980.

MIES, M. et al. Women: The Last Colony. Londres: Zed Books, 1988.

NICHOLSON, L. (org.). Feminism/Postmodernism. Nova York: Routledge, 1990.

ODIH, P. Watersheds in Marxist Ecofeminism. Capitalism Nature Socialism, vol. 27, n. 1, 2016, p. 132-140.

PIETILA, H. Tomorrow Begins Today: Alternative Development With Women in the North. ICDA/ISIS Workshop, Forum 85, Nairobi, 1985.

RICH, A. Of Woman Born. Nova York: Bantam, 1977.

SALLEH, A. An Ecofeminist Bio-Ethic: and what post humanism really means. New Left Review, n. 217, 1996, p. 138-147.

Contribution to the Critique of Political Epistemology. Thesis Eleven, n. 8, 1984, p. 23-43.

194 A tecnociência pós-moderna e o trabalho... 
Ecofeminism as Politics: nature, Marx, and the postmodern. Londres: Zed Books, 2017.

. Essentialism and Ecofeminism. Arena, n. 94, 1991, p. 167-173.

. Global Alternatives and the Meta-Industrial Class. In: ALBRITTON, R. et al. (orgs.). New Socialisms: Futures Beyond Globalisation. Londres: Routledge, 2004.

. On the Dialectics of Signifying Practice. Thesis Eleven, n. 5/6, 1982, p. 72-84.

. The Politics of Representation. Arena, n. 91, 1990, p. 163-169.

SHIVA, V. Staying Alive: Women, Ecology and Development. Londres: Zed Books, 1989.

SOFOULIS, Z. Through the Lumen: Frankenstein and the optics of reorigination. Universidade da California, Santa Cruz, 1988.

SOLON, P. (org.). Systemic Alternatives. La Paz: Fundación Solón / Attac France / Focus on the Global South, 2017.

SPIVAK, G. Other Worlds: Essays in Cultural Politics. Londres: Methuen, 1987.

STURGEON, N. Ecofeminist Natures. Nova York: Routledge, 1997.

WARING, M. Counting for Nothing. Sydney: Allen \& Unwin, 1988.

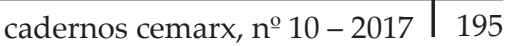


WARREN, K. The power and the promise of ecological feminism. Environmental Ethics, v. 12, 1990, p. 125-146.

WORLD RAINFOREST MOVEMENT. Resistances Struggles and Women's Voices Confronting Territories Destruction and False Solutions. WRM Bulletin, n. 231, 2017.

196 A tecnociência pós-moderna e o trabalho... 